\title{
Conhecimentos Prévios sobre Seres Vivos dos Estudantes das Séries Iniciais da Cooperativa de Ensino de Central - COOPEC- BA
}

Darcy Ribeiro de Castro

Nelson Rui Ribas Bejarano

\section{Resumo}

Este trabalho objetivou fazer um levantamento dos conhecimentos prévios dos alunos das Séries Iniciais da Cooperativa de Ensino de Central (COOPEC), cidade de Central-BA, em 2009. Este estudo envolveu conteúdos dos aspectos de seres vivos (identificação, tamanho e função). Para desenvolvê-lo, usamos o referencial vygotskyano acerca do desenvolvimento da criança, conhecimento espontâneo e científico, mediação, e outro biológico sobre os conceitos aprendidos na infância, dentro e fora da escola. Aplicamos questionários com perguntas gerais para as turmas com o intuito de obter informações sobre os conhecimentos prévios dos estudantes com respeito aos seres vivos; usamos fichas para registro de saberes adicionais dos alunos. Analisamos os dados, com base no método comparativo, em todas as turmas das séries iniciais, a partir das respostas dos alunos. Isso possibilitou identificar o que conhecem as crianças sobre os referidos aspectos de seres vivos, como ponto de partida para planejamento de ensino sobre o tema.

Palavras-chave: Séries Iniciais, conhecimento prévio, seres vivos, referencial vygotskyano, ensino.

\begin{abstract}
This study aimed to survey students' prior knowledge of Initial Series of Cooperative Education Center (COOPEC), Central City, Bahia, 2009. This study involved content aspects of living beings (identity, size and function). To develop it, use the vygotskyan reference about child development, spontaneous and scientific knowledge, mediation, and other biological about the concepts learned in childhood, in and out of school. Apply questionnaires with general questions to the classes in order to obtain information about the students ' previous knowledge with respect to living beings; use chips to record additional knowledge of students. We analyzed the data, based on the comparative method, in all classes of the Initial Series, from the responses of the students. This enabled the identification of children who know about these aspects of living beings, as a starting point for planning teaching on the subject.
\end{abstract}

Keywords: Initial Series, prior knowledge, life, reference Vygotsky, teaching. 


\title{
Introdução
}

Este trabalho faz parte da proposta de investigação intitulada "Estudo de Conceitos de Seres Vivos pelas Crianças das Séries Iniciais" na Cooperativa de Ensino de Central-COOPEC, dentro do programa de mestrado em Ensino, Filosofia e Historia das Ciências da Universidade Federal da Bahia-UFBA e Universidade Estadual de Feira de Santana-UEFS (Castro, 2010). Esta escola está localizada na cidade de Central, região Noroeste de estado da Bahia, a $510 \mathrm{~km}$ de Salvador.

Consideramos, como referencial para o desenvolvimento do presente estudo, trabalhos voltados para estudo dos conhecimentos espontâneos e/ou conhecimentos escolares da criança âmbito das ciências naturais (Children's..., 1992; Lawson, 1988; Driver, 1989; Freitas, 1989; Byrne e Sharp, 2006; Sforni e Galuch, 2006; Cunha e Justi, 2008; Popov, 2008; Castro, 2010; Castro e Bejarano, 2012; Castro e Bejarano, 2013).

Esses trabalhos estão de acordo com a diferenciação dos conhecimentos espontâneos e científicos proposta por Vygotsky (1991; 2000; 2010), bem como outros conceitos comuns da Teoria Histórico Cultural (mediação, zona de desenvolvimento) e em consonância com as fases do desenvolvimento por ele estudadas. Para este autor, os conceitos espontâneos surgem da reflexão da criança sobre suas experiências cotidianas, sendo aprendidos assistematicamente. A criança se desenvolve conceitualmente na medida em que consegue relacionar as palavras aos objetos a que se referem, prevalecendo, entre ambos, as relações direto-figuradas. Por outro lado, os conceitos científicos se originam em processos formais de ensino e aprendizagem, mediados por atividades estruturadas e especializadas e se caracterizam por formarem um sistema hierárquico de relações lógico-abstratas.

Todavia, há uma conexão recíproca entre os conhecimentos espontâneos e científicos, como descrito a seguir (João Luiz Gasparin ${ }^{1}$ ):

\begin{abstract}
"Segundo a Teoria Histórico-Cultural, os conceitos científicos se formam, no aluno, de maneira diversa dos espontâneos. Estes se desenvolvem de baixo para cima, partindo dos objetos vivos e reais, enquanto os científicos seguem um caminho inverso, ou seja, de cima para baixo, tendo seu ponto de partida nas propriedades mais complexas e superiores, descendo às mais elementares e inferiores. Neste processo, é de suma relevância a intervenção consciente do professor - a mediação. O educando, ainda que domine, na prática, o conceito cotidiano, demora para tomar consciência dele e a formulá-lo verbalmente. $O$
\end{abstract}

\footnotetext{
1 João Luiz Gasparin, A construção dos conceitos científicos em sala de aula. Disponível em:< http://www.pesquisa.uncnet.br/pdf/palestraConferencistas/A_CONSTRUCAO_DOS_CONCEITOS_ CIENTIFCOS_EM_SALA_DE_AULA.pdf >. Acesso em: 21 mar. 2009.
} 
contrário acontece com os conceitos científicos que partem da definição verbal e das operações mentais, conscientes, ligadas à elaboração dessa definição".

Trazer estes tipos de conhecimento para a escola, de forma que eles sejam utilizados para o desenvolvimento do pensamento conceitual dos estudantes, é um desafio a ser assumido por uma educação que prima pela formação de sujeitos conscientes, autônomos e que agem em resposta aos estímulos ou problemas do seu meio social.

Segundo Castro e Bejarano (2013) ${ }^{1}$, o uso de conhecimento das vivências cotidianas da criança como ponte para a construção do conhecimento científico diante da difícil realidade do ensino de Ciências no Brasil, em que a falta de professores habilitados é um dos problemas principais vinculados ao uso de conceitos científicos na escola pelos alunos. Nas Séries Iniciais, por exemplo, contamos apenas com cerca de $5 \%$ de pesquisas voltadas para o ensino de biologia, conforme assinala Teixeira (2007), num estudo desenvolvido sobre dissertações e teses na área do ensino de Ciências Biológicas no Brasil, no período de 1972 a 2004.

Com base nesse autor, percebemos que essas duas questões merecem uma atenção especial porque o baixo percentual de pesquisa sobre a referida área de conhecimento pode limitar o acesso dos professores a tal tipo de formação, até mesmo os já licenciados. Assim, além da falta de professores com formação em biologia, temos aqueles que embora habilitados na área, não estão capacitados para levar aos estudantes um ensino baseado nos seus conhecimentos espontâneos, como meio para elaboração do saber científico.

O Estudo da temática envolvendo conceitos de micro-organismos, animais e plantas (tamanho, morfologia, ciclo vital e crescimento) para tal etapa de ensino pode apresentar, em especial, uma possível contribuição para ampliar as pesquisas e o ensino de Biologia nas primeiras séries do ensino fundamental. Para isto, o nosso trabalho de investigação em sala de aula, com os alunos do Ensino Fundamental I da COOPEC buscou identificar os conhecimentos que eles podem oferecer à escola e aos professores no tocante a um ensino de ciências que valorize o ser humano como parte integrante do seu meio, enquanto sujeito que aprende coisas importantes e concretas, reflete, age, resolve problemas, a partir da escola (Castro, 2010).

Esses, sem dúvida, segundo Sforni e Galuch (2006), são aspectos importantes quando se objetiva promover o estudo dos problemas reais da educação, a partir das dificuldades e potencialidades dos alunos. Todavia, não podemos substituir aprendizagem conceitual por normas de atitudes e de comportamentos adquiridos espontaneamente pelos estudantes.

${ }^{1}$ CASTRO, D. R.; BEJARANO, N. R. R. Os conhecimentos alternativos e científicos na área de ciências naturais: uma revisão a partir da literatura internacional. Ciência \& Educação, v. 19, n. 1, p.1015-1028, 2013 (prelo). 
Entendemos que sem conhecimento de conceitos científicos correlatos aos espontâneos, tais conteúdos perdem o seu valor de ação consciente e de prática concreta diante da realidade. Por outro lado, o saber científico geralmente transmitido na escola como apenas "receitas" prontas não favorece ao desenvolvimento conceitual dos estudantes, nem tampouco os fortalece na direção de enfrentamento de problemas do cotidiano.

Dessa forma, o ensino, mesmo que fundamentado em pesquisas científicas, acaba ampliando mais a distância entre os mundos do conhecimento cotidiano e científico. Desta forma, acaba a essência do conhecimento de conceitos sendo reduzida a frases sem sentido para a ciência, do tipo: "os micróbios não servem para nada", "os micróbios só trazem doenças ao ser humano" etc.. Mudar essa realidade é um desafio da escola, e, para isto, distanciar das formas de exclusão do saber e propiciar alternativas para superação da falta de conhecimento científico é diferencial para o desenvolvimento do pensamento conceitual da criança a partir da relação entre os conteúdos concretos e abstratos desenvolvida dentro ou fora da escola (Sforni e Galuch, 2006).

Conhecer os saberes cotidianos das crianças, em relação aos assuntos mencionados, poderá ser um potencial meio para planejar as atividades de ensino para elas, bem como facilitar a mediação dos conceitos científicos a serem ensinados em sala de aula. Dessa forma, a teoria científica poderá ser assimilada à medida que o conhecimento prático é oportunizado a criança numa relação em que o conteúdo teórico que se espera que o professor ensine aos seus alunos, seja concretizado em atividades práticas, as quais poderão suscitar novas explicações teóricas ao professor (Castro, 2010).

\section{Fundamentação teórica}

$\mathrm{Na}$ escola COOPEC, observamos como as crianças das Séries Iniciais demonstram o conhecimento sobre alguns conteúdos de Ciências Naturais, considerando micro-organismos, animais e plantas (tamanho, morfologia, ciclo vital e crescimento). Elas usam ferramentas do cotidiano, falam, desenham, escrevem e interrogam os professores sobre as questões que acham interessantes no seu contexto de vida.

A criança vê o mundo a cada momento de uma forma diferente, a partir da experiência que vivencia, e nesse processo, vai construindo seu conhecimento sobre a realidade. Este conhecimento prévio, também fruto da experiência do dia-a-dia, favorece a formação do senso comum e sua contribuição para a formação humana é limitada. Para alterar esta realidade, a escola precisa oportunizar conhecimentos e meios para que meninos e meninas possam avançar na sua formação crítica e funcional através do conhecimento científico (Castro, 2010).

Para isto, é necessário considerarmos a evolução das formas de pensamento da criança estudadas por Vygotsky $(1991 ; 2000 ; 2010)$ vinculadas aos estágios de desenvolvimento e a 
relação com a aprendizagem escolar. Em igual razão, enfatizamos a diferenciação entre os conhecimentos espontâneos e científicos é fundamental (Castro, 2010).

Neste sentido, os processos que levam à formação de conceitos evoluem ao longo de duas linhas principais. A primeira é a formação dos complexos: a criança agrupa diversos objetos sob um "nome de família" comum; esse processo passa por vários estágios. A segunda linha de desenvolvimento é a formação de "conceitos potenciais", baseados no isolamento de certos atributos comuns. Em ambos os casos, o emprego da palavra é parte integrante dos processos de desenvolvimento, e a palavra conserva a sua função diretiva na formação dos conceitos verdadeiros, aos quais esses processos conduzem (Vygotsky, 1991; 2000; 2010).

A criança de 7/8 anos não tem consciência e deliberação para opinar sobre os fatos; usa a conseqüência em vez da causa para explicar os fenômenos, como ilustram os exemplos (Vygotsky, 1991, p.110) a seguir: "amanhã não vou à escola porque estou doente" (não deliberação)... "o homem caiu de bicicleta porque quebrou o braço" (conseqüência). Para clarear essa situação, Vygotsky $(1991 ; 2000 ; 2010)$ assegura que a percepção das diferenças vem primeiro do que as semelhanças, pois as similaridades entre os objetos não provocam reação que envolva consciência na criança, enquanto as características distintivas entre eles causam inadaptação que conduz à percepção.

A percepção consciente da semelhança pressupõe a formação de um nível de generalização maior ou de um conceito que abranja todos os objetos semelhantes, enquanto a consciência da diferença não exige tal generalização (Lei das diferenças e semelhanças). A partir disto, as crianças no momento em que se pede que elas definam algo passam a defini-lo pelo o que não é, não apontando as similaridades dos objetos (Vygotsky, 1991; 2000; 2010).

O desenvolvimento do pensamento de crianças de 07 a 12 anos pode ser explicado por essa lei, pois os conflitos entre as operações mentais delas com os adultos, a dificuldade lógica e as suas experiências dolosas resultantes dessa fase criam a necessidade do uso dos conceitos (Vygotsky, 1991; 2000; 2010).

Vários estudos mostraram que é no início da idade escolar que as funções intelectuais superiores, cujas características principais são a consciência reflexiva e o controle deliberado, adquirem um papel importante no processo de desenvolvimento. A atenção e a memória tornamse lógicas e voluntárias como processos controlados em função da consciência dos mesmos. No início do período escolar, essas funções eram utilizadas e praticadas inconsciente e espontaneamente. A criança no início do período escolar tem as funções, a partir das quais ela aprende a submeter o controle consciente no momento que os pré-conceitos começam a se originar dos complexos (Vygotsky, 1991; 2000; 2010).

Embora o referencial de Vygotsky e muitos trabalhos a ele relacionados apresentem argumentos sobre o desenvolvimento dos conceitos científicos, eles ainda carecem de situações 
experimentadas na escola, especialmente no tocante ao estudo do tema proposto. Entretanto, mesmo apresentando fortes subsídios para ajudar na compreensão dos processos referentes à formação de conceitos, encontra obstáculos no sistema escolar brasileiro quase que instransponíveis, como é o caso da falta de professores habilitados e de materiais didáticos adequados para auxiliar num ensino que contribua para o desenvolvimento conceitual dos alunos.

Quanto ao último ao último obstáculo, podemos afirmar que os livros didáticos, programas, manuais do professor adotados no Brasil ainda é regido pela supressão dos pensamentos, das suas experiências e formas de expressão (desenhos, questionamentos...) e da cultura dos alunos. Isto favorece o distanciamento entre a escola e o meio extra-escolar (cotidiano), diminuindo a viabilidade de ampliação do pensamento conceitual das crianças, uma vez que sabemos que o ensino possibilita a formação dos conceitos científicos a partir dos saberes espontâneos delas, sendo que os conceitos formados também influenciam na elaboração de novos conhecimentos cotidianos (Vygotsky, 1991; 2000; 2010).

Estes materiais didáticos parecem não contemplar grande parte dos requisitos, ora suprimidos nas diferentes realidades brasileiras. Por outro lado, as pesquisas acadêmicas (teses, artigos, etc.) não chegam efetivamente às escolas o que dificulta avanços na área do ensino de ciências. Não há uma valorização do aluno, o objeto central de todo ensino, quanto à sua experiência de mundo, os seus pensamentos, os seus conceitos, as suas explicações, as suas maneiras (conceitos cotidianos) de refletir e de se referir a esse mundo (Castro, 2010).

Popov (2008) esclarece melhor a questão anteriormente citada ao afirmar que a criança na escola reflete visões de dois "mundos" bastante isolados um do outro: um em que ela traz informações da família, amigos, comunidade, dos meios de comunicação e da natureza; outro do qual ela traz saberes da sala de aula, dos colegas, professor e do ambiente escolar. 0 primeiro é o mundo prático (senso comum) que funciona na vida cotidiana, viabilizado pela imitação que as crianças fazem aos adultos ou de alguém que conhece os conteúdos que fazem parte da vida extra-escolar, enquanto o segundo tenciona preparar desde cedo o aluno para vida acadêmica e burocrática do meio social mediado pela repetição dos conteúdos escolares, que pouco tem a contribuir para o desenvolvimento conceitual dos alunos.

Ainda hoje, as escolas parecem adotar um sistema de aprendizado que favorece aplicação de problemas que a criança consegue resolver sozinha ou não dirigir a criança para o que ainda ela não é capaz de fazer. "O aprendizado voltava-se para as deficiências da criança, ao invés de voltar para os seus pontos fortes, encorajando-a, assim, a permanecer no estágio pré-escolar do desenvolvimento" (Vygotsky, 1991, p.130). Para este autor, um bom ensino é aquele que provoca mudanças qualitativas no pensamento dos alunos durante o período escolar, ou seja, a escola promove o aprendizado de operações que favorecem o desenvolvimento da consciência e do controle deliberado da criança Isso aplica também ao desenvolvimento dos conceitos científicos que o aprendizado escolar pode apresentar à criança. 
A finalidade deste trabalho de investigação, portanto, não se limita estudar a aquisição de um conceito científico como produto pronto e acabado. Mais importante nesta dimensão é a valorização dos conhecimentos prévios dos alunos, das formas de expressão das suas concepções espontâneas e dos novos conhecimentos adquiridos ao longo da escolaridade nas Séries Iniciais. Consideramos neste trabalho os conhecimentos espontâneos e científicos como conhecimentos prévios, pois se trata estudo de dados apresentados pelos alunos (diagnóstico) antes da realização da pesquisa interventiva em que se levou em conta as aulas ministradas pelas professoras da COOPEC e pelo pesquisador ( $2 \circ$ ao $5 \circ$ ano). Levamos em conta ainda os conhecimentos científicos estudados por Vygotsky (1991; 2000; 2010) como escolares e ainda os espontâneos como cotidianos, conforme nos assegura (Duarte, 2003; Popov, 2008).

Por isso, buscamos identificar os conhecimentos prévios dos alunos sobre os conceitos de seres vivos, envolvendo micro-organismos, animais e plantas (tamanho, morfologia, ciclo vital e crescimento) na escola COOPEC durante o ano letivo de 2009. Isto na perspectiva de possibilitar o professor conhecer melhor as dificuldades e as potencialidades de compreensão dos alunos (pontos fracos e fortes) sobre tais conteúdos para fins de elaborar, com base nessas questões, o planejamento de um ensino para professores (as) da referida escola. Para isto, contamos com o apoio das professoras desta escola para a realização deste trabalho, com o intuito de utilizá-lo para ajudar no cumprimento da principal finalidade da escola que é desenvolver um trabalho voltado para a preparação do indivíduo, no sentido de torná-lo apto para compreensão e enfrentamento dos problemas cotidianos, bem como sua auto-realização (Castro, 2010).

Consideramos ainda para tal questão que os alunos têm familiaridade com uma série de conceitos científicos, mas o aprofundamento deles, a conexão com pensamentos mais amplos e princípios científicos é extremamente limitado. Há uma lacuna muito grande entre o conhecimento científico e os conhecimentos espontâneos dos alunos. De acordo com Tanner e Allen (2005), esse problema reside na diferença entre o conhecimento dos conteúdos ensinado na escola e a sua compreensão correspondente pelos alunos. Acreditamos que conhecendo a concepções espontâneas dos alunos em relação aos conceitos de micro-organismos, animais e plantas pode sinalizar avanços na direção de minimização de tal impasse na COOPEC e servir para análise de situações análogas às que vivem as crianças da referida escola, em outros contextos que fazem parte do ensino de ciências nas Séries Iniciais.

Castro e Bejarano (2013) realizaram um trabalho de revisão bibliográfica sobre microorganismos, funções vitais de animais e plantas que destacou 02 (duas) abordagens consensuais e gerais em que considera: 1) um bom número de conhecimentos espontâneo nas crianças que fizeram parte das pesquisas; 2) pouco conhecimento espontâneo acerca dos seres vivos. Neste trabalho, percebemos que os conceitos biológicos espontâneos apresentados acerca de microorganismos (Castro, 2010; Byrne e Sharp, 2006; Driver (1989); Freitas 1989; C), vegetais (Castro, 2010; Children's..., 1992) e animais (Castro, 2010; Cunha e Justi, 2008) indicaram sobremaneira 
um ponto de partida para a aquisição dos conceitos científicos correspondentes para as crianças. Por outro lado, observamos que autores como Lawson (1988), Popov (2008), ao afirmarem que há poucos conhecimentos espontâneos acerca dos aspectos conceituais supracitados, reiteram que isto em quase nada contribui para o ensino dessas temáticas na escola.

Segundo Lawson (1988), há pouco êxito nos trabalhos sobre os conceitos espontâneos dos alunos no tocante às ciências biológicas, principalmente, no ensino voltado para crianças. Este autor assegura que nesta área, os conhecimentos biológicos espontâneos são altamente enraizados, complexos e parece não encontrar um núcleo comum (elo) entre a experiência pessoal e as visões cientificamente errôneas, a exemplo da dificuldade de distinção entre os conceitos de seres vivos e não vivos.

Popov (2008), numa pesquisa realizada nas escolas de Moçambique, sobre a diferenciação entre seres vivos e não vivos, a partir da sua composição celular, mostrou os seguintes resultados: mais de $50 \%$ de alunos identificou corretamente que os corpos de animais e plantas são constituídos por células; 80 \% dos alunos afirmaram que coração é constituído por células; $39 \%$ dos alunos dizem que o ar é constituído por células e 33\% deles diz o mesmo acerca da água. Isto significa que os alunos relacionam facilmente os seres vivos ou suas partes (órgãos) como sendo constituídos por células, mas quanto ao ar e a água, estas respostas parecem estar vinculadas ao animismo que está presente na cultura da sociedade africana.

Freitas (1989) num estudo realizado com crianças de 7 a 14 anos de idade numa escola de Portugal (Braga) fez a distinção entre seres vivos e seres não vivos, a partir da definição do conceito de ser vivo. Para isto, este autor considerou, como critérios mais importantes, os conhecimentos dos alunos sobre propriedades gerais da vida (ciclo vital), movimento, tautologia, classificação, antropomorfismo, teoria celular, dentre outros. 0 estudo indicou que a maioria das crianças usou as propriedades gerias da vida para a definição de ser vivo $(89,7 \%)$, sendo que $100 \%$ delas as tomaram como base para diferenciar seres inanimados de seres vivos. Este trabalho mostrou ainda que as crianças do 30 ano apresentaram melhores resultados (conhecimento científico) na diferenciação de seres vivos e não vivos do que as crianças do 6ㅇ e 70 ano.

Esta questão é explicada pelas seguintes razões: o ensino ofertado para crianças menores considera um menor numero de critérios; após o 6으 ano, o ensino requisita, além dos critérios mencionados, mais conhecimento dos alunos acerca da teoria celular para fins de definição de um ser vivo, e, consequentemente, para diferenciá-lo de um ser inanimado (bruto). Freitas (1989) acrescenta ainda que a falta de experiência dos estudantes no que tange ao conhecimento microscópico da célula e/ou de seres vivos microscópicos poderá dificultar a compreensão dos conceitos de tamanho e funcionalidade de seres vivos nas séries mais adiantadas.

Byrne e Sharp (2006), num estudo sobre micro-organismos com crianças de 7, 11 e 14 anos de idade em escolas da Inglaterra, mostraram que todos os alunos envolvidos na pesquisa 
concebem os micro-organismos apenas como causadores de doenças e que a maioria das atividades de ensino não trazem êxito para a mudança de pensamento dos alunos. Estes autores consideram em seu trabalho os seguintes aspectos conceituais acerca dos micro-organismos: origem e estrutura, tamanho, habitat e função. Eles afirmam que as respostas corretas para estes itens foram aumentando com idade da criança; atribuem este fato ao tempo maior em que as crianças mais velhas passaram na escola e o contato com outros contextos que contribuem para aprendizagem, como a televisão, revistas, anúncios, cartões etc..

Os referidos autores acrescentam que, embora as crianças maiores já diferenciem os aspectos de células individualizadas e múltiplas células, elas ainda não avançam na descrição da estrutura celular e funcionalidade, no sentido de aproximação com descrição científica dos livros de ciências. Driver (1989) reitera este ponto de vista ao considerar que as contraditórias e negativas ideias são comuns nos alunos mais velhos, quando submetidos a vários contextos $\mathrm{e}$ escolaridade.

Byrne e Sharp (2006) afirmam que muitas crianças reconhecem os micro-organismos como seres vivos a partir do movimento que eles realizam que é a principal característica vital destes seres tão pequenos. O movimento é mais associado a animais do que a plantas, o que leva as crianças a pensar nos micro-organismos como seres vivos que fazem parte do Reino Animal. Elas apenas têm a noção destes seres vivos como alguma coisa que existe, mas ainda invisível ao olho nu, e, particularmente, difícil de agarrar. As crianças de 7 (sete) anos sugerem que os microorganismos são "finos", "invisíveis" ou "muito pequenos", e que não podem ser vistos em pequenos espaços. Dos 11 anos de idade em diante, a maioria das crianças referencia os microorganismos como seres microscópicos, reais e pequenos, e que são capazes de reproduzir. Essas crianças usam CD, TV, Computador, internet para obtenção de tais conhecimentos, mas estes recursos têm muito pouco impactos no crescimento conceitual destas crianças.

Lawson (1988) realizou estudos com crianças com idade de 6, 9 e 10 anos numa escola suburbana norte- americana de classe média. Ele concluiu que a visão dos alunos acerca dos conceitos de crescimento de animais e plantas não são uniformes. As crianças de 6 e 9 anos acreditam que os animais crescem pela comida (alimento) e as plantas crescem através da água que absorvem do solo (pensamento espontâneo). Apenas a criança de 10 anos tem alguma ideia de que animais e plantas crescem a partir das divisões celulares. Este saber não foi derivado de observações diretas dos alunos, e sim da transmissão dos conteúdos feita pelo professor (conhecimento declarativo dogmático).

Cunha e Justi (2008), num estudo sobre digestão e nutrição com crianças do Ensino Fundamental I, afirmam que apesar dos alunos deste nível de ensino possuir conceitos científicos sobre o tema, os conceitos adquiridos por eles na vida cotidiana influenciam muito a descrição (desenhos e analogias) que fazem sobre as estruturas do sistema digestório e a dinâmica da digestão dos alimentos. Vale destacar que, segundo estes autores, as características perceptíveis 
no ambiente são analogias estruturais, enquanto as que não têm referentes concretos observáveis são funcionais. Podemos ter como exemplo que para conteúdos concretos (intestino $X$ vasos de flores), elas recorrem a analogias estruturais e, em situações abstratas (pílula $X$ energia), elas adotam as analogias funcionais.

De acordo a pesquisa "Children's ideas about living things" (1992), muitas crianças não distinguem entre as propriedades do corpo humano e suas partes constituintes. Elas compreendem apenas as funções estáticas dos órgãos: o coração é para amar; o cérebro é para pensar. De acordo com Vygotsky (1991; 2000; 2010), observamos que estas crianças usam o egocentrismo para se referir a tais estruturas do corpo.

\section{Metodologia}

A investigação envolveu 63 alunos das Séries Iniciais e 04 professores (as) deste nível de ensino da Cooperativa de Ensino de Central (COOPEC), sendo: 03 professores de 2ㅇ ao 4으 ano (01 por série) e 01 de ciências do 5ำ ano. Trata-se de um estudo com crianças na faixa etária de 07 a 11 anos que não tiveram, até o momento de realização deste trabalho, passado por experiências sistematizadas e/ou uso de microscópios nas aulas de Ciências. As professoras das Séries Iniciais têm formação em magistério de 1으 grau ( 2 ㅇ ano); licenciatura em pedagogia (3ㅇ); licenciatura em letras (4ㅇ ano) e licenciatura em biologia (5 ano), conforme assinala o Castro (2010).

A escola pesquisada tem como missão desenvolver um trabalho voltado para a preparação do indivíduo (aluno), a partir do desenvolvimento das suas formas de pensamento, mesmo considerando as dificuldades de ensino da mesma quanto à falta de laboratório e materiais práticos alternativos que podem ser usados para a realização de experiências. A COOPEC atende crianças filhas de funcionários públicos municipais da sede e povoados que sua maioria tem dificuldades financeiras. Por isso, as atividades dos professores e demais funcionários têm participação de voluntários (Castro, 2010).

A partir da primeira etapa da pesquisa de Mestrado, identificamos e analisamos os conhecimentos prévios acerca de conceitos de seres vivos dos estudantes das Séries Iniciais da COOPEC. Para concretizar estes objetivos, aplicamos questionários nas 04 (quatro) turmas de Ensino Fundamental, com questões generalistas (questionário geral- qg1) para fins de levantamento dos conhecimentos prévios dos alunos no inicio do 10 bimestre do ano de 2009 . Consideramos os seguintes conteúdos para elaboração do instrumento de pesquisa qg1: seres vivos e não vivos e suas propriedades, ciclo de vida, classificação, alimentação e crescimento (Castro, 2010).

Distribuímos também junto aos questionários (qg1) fichas para depoimento dos alunos acerca dos assuntos envolvido na pesquisa nas quais eles emitiram, de uma forma geral, informações/questionamentos acerca das aulas ministradas pelas professoras da COOPEC, a 
saber: experimentos sobre a germinação do feijão em algodão úmido, "mofo no pão" e estudo de ambiente no pátio, horta, entorno da referida escola e lagoa da prefeitura. Servimo-nos da ficha com a intenção de obter com os alunos informações complementares ao questionário.

Para atender ao propósito deste trabalho, aplicamos inicialmente o qg1 para 08 alunos da COOPEC para fins de validação deste instrumento de pesquisa. Para isto, foi necessário o preparo do ambiente de pesquisa com os alunos em sala de aula através da apresentação dos objetivos e da importância da pesquisa para escola, dentre outras ações (Castro, 2010).

Iniciamos o trabalho investigativo no nível de desenvolvimento atual (real) de conhecimento (espontâneo) dos alunos (Gasparin, 2009). A coleta de dados realizada na COOPEC, para fins de diagnóstico, teve duração de (04 h/aula) sendo 1h/aula por turma (qg1), incluindo o preenchimento das fichas de depoimento. Em cada turma foram aplicados questionários (qg1) e distribuídas as fichas de depoimento para que eles descrevessem suas concepções acerca dos conteúdos supracitados referentes aos micro-organismos, animais e plantas, tendo como conteúdo/categorias, o tamanho, morfologia, crescimento e função.

Os dados coletados nesta pesquisa foram analisados, com base na orientação do método dialético (GASPARIN, 2009), enfatizando a comparação das respostas dos alunos.

O método dialético de elaboração do conhecimento científico escolar tanto pode ser posto em prática como princípio geral de todo processo de ensino e aprendizagem, quanto na construção mais específica dos conceitos em si. Em ambos os casos, o ponto de partida do trabalho pedagógico é a Prática Social Inicial do conteúdo. Gasparin (2009) menciona as três fases do método dialético de construção do conhecimento escolar: Prática-teoria-prática, partindo do nível de desenvolvimento atual dos alunos, trabalhando na zona de desenvolvimento imediato (proximal) ${ }^{1}$, para chegar a um novo desenvolvimento atual. No caso do levantamento dos conhecimentos prévio em questão, seguimos o primeiro passo que trata da Prática Social Inicial do conteúdo ou do conceito que se expressa pela vivência cotidiana na totalidade empírica.

O princípio geral do processo de ensino e aprendizagem diz respeito às concepções de conteúdos gerais que fazem parte do meio social da criança e que permeia a concepção de ensino na instituição pesquisada. Tais conteúdos, ao serem sistematizados na sala de aula, nas disciplinas específicas a partir da teoria científica correlata poderão suscitar novos pontos de partida para o trabalho escolar. A noção de tamanho e função de seres vivos que as crianças trazem a escola é o ponto de partida que traz uma conotação social e histórica sobre o assunto; o conteúdo do livro

\footnotetext{
${ }^{1}$ Usamos o termo zona de desenvolvimento proximal como a distância entre o conhecimento que o estudante sabe num dado momento antes de se realizar uma atividade de ensino (zona de desenvolvimento real ou atual) e o que ele poderá passar, a saber, (zona de desenvolvimento potencial) após a realização de tal tarefa (Vygotsky, 2000, p.374).
}

R. B. E. C. T., vol. 6, núm. 1, Jan-Abr.2013 ISSN - 1982-873X 
de ciências ensinado pelo professor possibilita outro aspecto de conhecimento do aluno para o qual se requisita novos conceitos teóricos na sua explicação (Castro, 2010).

Em cada série, fizemos a comparação das respostas dos alunos de acordo com cada item do questionário/depoimento paras diferentes questões que compunham o instrumento (qg1), tendo em vista a verificação de conteúdos/categorias que os alunos apresentaram mais dificuldades de compreensão. Vale ressaltar que consideramos as respostas originais dos estudantes, incluindo erros ortográficos e/ou neologismos nas respostas aos itens destes referidos questionários e também nos depoimentos. Com o diagnóstico adquirido com aplicação das questões referentes à qg1 e aos registros complementares das fichas de depoimento, descrevemos a prática inicial dos conteúdos proposta por Gasparin (2009).

Com a pesquisa exploratória de caráter qualitativo (Bogdan; Biklen, 1994) a qual nos servimos neste trabalho, buscamos dar respostas para as questões levantadas pelos questionários (qg1) e fichas de depoimentos sobre o problema da compreensão dos conceitos de seres vivos pelas crianças em relação às dificuldades enfrentadas pela escola COOPEC, no que tange a realização de aulas práticas (falta de laboratório e material prático alternativo). Para isto, consideramos os conceitos adquiridos pelos alunos a partir de um ensino realizado durante 04 (quatro) anos pelas docentes, envolvendo os conteúdos supramencionados, bem como os conhecimentos trazidos por eles da vida cotidiana em relação a tais assuntos.

Esta pesquisa com os alunos ganhou força à medida que os dados demonstraram suficientes como alternativas para auxiliar as professoras da COOPEC na ampliação das suas práticas, no sentido de planejar e exercitar melhor sua atividade profissional. Assim, como afirma Duarte (2003), o professor reflexivo poderá adotar uma pedagogia não pautada "apenas" no saber escolar (representações formais) e concentrar sua ação nas "representações figurativas" contida no conhecimento-ação dos alunos (conhecimento cotidiano, tácito). Esses conhecimentos dos alunos foram evidenciados à medida que eles ofereceram à escola suas formas de compreensão acerca dos conceitos de seres vivos trazidos da experiência diária (Castro, 2010).

Pines e West (1984) argumentam que uma maneira eficaz para avaliar o nível de conhecimento dos alunos é a partir das situações de aprendizagem escolar: situação formalsimbólica/zero - espontânea e situação espontânea/não instruída. A primeira ocorre quando existe pouco conhecimento espontâneo para interagir com o conhecimento formal apresentado na escola; na segunda, o conhecimento espontâneo é extenso, rico e suficiente e não há conhecimento escolar correspondente a ser apresentado.

Para o nosso trabalho investigativo, usamos estas situações de aprendizagem as quais podem nos auxiliar na distinção entre os pontos fortes e fracos dos alunos. 


\section{Conhecimentos prévios dos alunos da COOPEC sobre seres vivos}

No tocante às dificuldades encontradas pelas professoras da COOPEC em sala de aula (falta de laboratório e materiais alternativos para aulas práticas), quanto aos aspectos de seres vivos propostos, observamos que alguns conteúdos sobre os quais as crianças têm mais interesses e são curiosas, não são contemplados nas aulas ministradas por elas. Os experimentos e atividades desenvolvidas pelas docentes (germinação do feijão, "mofo no pão"...) não são suficientes para responder aos questionamentos dos alunos e/ou suscitar neles novas questões de aprendizagem, o que minimiza a possibilidade de ampliação na compreensão dos conteúdos por eles. Dessa forma, percebemos um descompasso entre o conhecimento escolar (científico) e o conhecimento espontâneo, presente no cotidiano dos alunos (Castro, 2010).

A busca para conhecer o que os alunos sabem em relação aos conteúdos de seres vivos supracitados, a partir de seus conhecimentos prévios, pode representar uma alternativa importante para auxiliar na formação de conceitos pelas crianças das Séries Iniciais. A análise dos questionários contendo questões genéricas sobre os seres vivos e das fichas de depoimento, mostrou 2 (duas) categorias importantes em nível de especificidade de conteúdo: a noção de tamanho, e, principalmente, funções de seres vivos. Eles evidenciaram um conhecimento considerável nos conteúdos identificação dos seres vivos, na distinção entre ser bruto e ser vivo, ciclo de vida e, nas diferenças entre animais e plantas (Castro, 2010).

Nas questões referentes ao tamanho e às funções vitais de seres vivos, como alimentação, crescimento, respiração, configurou-se, de acordo com o Quadro 1, uma possibilidade para estudo das necessidades de aprendizagem das crianças, ou seja, propiciar condições para o ensino, a partir do que os alunos não sabem para o que eles precisam saber. Percebemos duas situações nesta direção: uma em que falta conhecimento prévio por parte dos alunos (as) sobre algumas questões (conceito A/I, QUADRO 2) e, outra em que tal conhecimento se apresenta de forma regular (R), ou suficiente (S). Estas questões podem ser usadas para auxiliar na identificação dos grupos de seres vivos (Castro, 2010). 


\section{0 conhecimento espontâneo dos alunos}

\begin{tabular}{|c|c|c|c|c|c|c|c|c|c|c|c|c|}
\hline QUESTÕES/ SÉRIES & \multicolumn{3}{|c|}{ 20 ANO } & \multicolumn{3}{|c|}{ 3 ANO } & \multicolumn{3}{|c|}{ 4 ANO } & \multicolumn{3}{|c|}{ 5o ANO } \\
\hline Níveis/respostas & I/A & $\mathbf{R}$ & $\mathbf{S}$ & I/A & $\mathbf{R}$ & $\mathbf{S}$ & I/A & $\mathbf{R}$ & $\mathbf{S}$ & I/A & & \\
\hline $\begin{array}{c}\text { 1- Qual dos seguintes } \\
\text { corpos são seres vivos? } \\
\text { Pedra, flor, água, } \\
\text { coração, planta... }\end{array}$ & 2 & - & 9 & 1 & 4 & 7 & 5 & 6 & 8 & 1 & 3 & 10 \\
\hline $\begin{array}{l}\text { 2- Como se diferencia um } \\
\text { ser vivo de um ser bruto? }\end{array}$ & - & - & 11 & 1 & - & - & 14 & - & 5 & 3 & - & 11 \\
\hline $\begin{array}{c}\text { 3- Existem seres vivos tão } \\
\text { pequenos que não } \\
\text { podemos ver? Quais? } \\
\text { Fale um pouco deles. }\end{array}$ & 11 & 4 & 6 & 3 & - & 9 & 6 & - & 13 & 2 & - & 12 \\
\hline $\begin{array}{l}\text { 4- Como é o ciclo de vida } \\
\text { dos seres vivos? Explique. }\end{array}$ & 2 & - & 9 & 1 & - & 11 & 12 & - & 7 & 4 & - & 10 \\
\hline $\begin{array}{l}\text { 5- De que forma você } \\
\text { diferencia um animal de } \\
\text { uma planta? }\end{array}$ & 4 & - & 7 & 3 & - & 9 & 8 & - & 11 & 3 & - & 11 \\
\hline $\begin{array}{l}\text { 6- Como se alimentam e } \\
\text { crescem? Um animal, } \\
\text { uma planta e você? }\end{array}$ & 3 & - & 8 & 3 & - & 9 & 4 & 3 & 12 & 3 & - & 11 \\
\hline TOTAL DE ALUNOS-56* & & 11 & & & 12 & & & 19 & & & 14 & \\
\hline
\end{tabular}

QUADRO 1 - Fonte: COOPEC, Central-BA, 2009-07 alunos ausentes - total de 63*

LEGENDA: Trata-se de conhecimentos espontâneos e escolares, I/A= ausência ou insuficiência das respostas dos alunos, $R=$ respostas regulares dos aluno, $S=$ Respostas suficientes dos alunos,- = ausência de resposta dos alunos

Os estudantes que possuem conhecimentos prévios regulares denotaram saberes em parte com e sem sentido numa mesma resposta, formando frase com raciocínios incompletos. Como exemplo, temos: no $2 \stackrel{0}{\text { ano, }} 04$ alunos emitiram resposta para a 3 a questão em que 
misturavam seres microscópicos com seres macroscópicos numa mesma resposta; no 3ำ ano, na 1a questão, 04 estudantes deram metade das respostas em que seres vivos e seres não vivos compartilhavam a mesma classificação (Castro, 2010).

Os estudantes que possuem conhecimentos prévios suficientes e apresentaram respostas completas ou com sentido para as questões inquiridas. Como exemplo, 09 alunos do 20 ano souberam identificar corretamente todos os seres vivos e não vivo e 11 alunos desta série souberam diferenciar esses seres a partir de suas características ("um ser vivo se alimenta e um ser bruto ou não vivo não se alimenta").

Em linhas gerais, a maioria dos alunos tem conhecimento espontâneo suficiente para os itens perguntados. Observa-se que pelo menos 02 alunos em cada série ( 2 ㅇ ao 50 ano) não associam os órgãos, ou parte dos seres vivos como seres vivos/estruturas vivas (questão 01). Aparece no 2 ㅇ e 5o ano a diferenciação entre um ser vivo e um ser bruto, a partir de uma "funcionalidade espontânea", ou seja, "um ser bruto é valente"; "um ser vivo é normal", ou ainda associando características anatômicas como, "um ser vivo tem coração, uma pedra não tem". Com base em Cunha e Justi (2008), o primeiro se refere ao uso de uma analogia funcional pela criança, enquanto o segundo exemplo se refere ao uso de uma analogia estrutural. As características que são perceptíveis no ambiente são analogias estruturais e as que não têm exemplos observáveis, são funcionais (Castro, 2010).

Há muitos conhecimentos espontâneos e pouco conhecimento escolar acerca dos conceitos de seres vivos em geral (QUADRO 1). Segundo Pines e West (1984), esse tipo de aprendizagem é classificado como situação espontânea/não instruída, pois o conhecimento espontâneo é extenso, rico e suficiente e não há conhecimento escolar correspondente a ser apresentado. Isto se explica devido em todas as séries, os níveis de respostas suficientes (s) denotam uma predominância dos conhecimentos espontâneos sobre os escolares. Este quadro começa a se alterar no 5 o ano para alguns conceitos de seres vivos (tamanho/função), especialmente em relação aos micro-organismos (QUADRO II, p.14/15).

Amaioria dos (as) discentes do 2음 ao 5 ano apresenta conhecimentos espontâneos sobre os aspectos identificação/tamanho/função dos seres vivos microscópicos (exceto o 20 ano), quando inquiridos sobre a questão 03, o que sugere uma deficiência em nível de correlação de tais aspectos com os conteúdos que se espera ser tratados em sala de aula, como exposto na descrição a seguir: 


\section{Reconhecendo os microorganismos}

\begin{tabular}{|c|c|c|}
\hline ANO & № DE ALUNOS (AS)- IDENTIFICAÇÃO & DESCRIÇÃO/ FUNÇÃO \\
\hline 20 & $\begin{array}{l}\text { 4- micróbios } \\
\text { 5- micróbios/bactérias }\end{array}$ & - Doenças- febre p.ex.. \\
\hline 3⿻ & $\begin{array}{c}\text { 2- bactérias/ vermes } \\
4 \text { - micróbios } \\
\text { 3- mosquitos, formiga, pulga }\end{array}$ & $\begin{array}{c}\text { - pulga é um animal bem } \\
\text { pequeno e vive em um } \\
\text { cachorro. }\end{array}$ \\
\hline 40 & $\begin{array}{l}\text { 2- micróbios } \\
\text { 11-cobra, mosquito, mosca, rã, minhoca, pulga, aranha }\end{array}$ & $\begin{array}{l}\text { - mosquito, eu não } \\
\text { encontro porque ele é } \\
\text { muito pequeno. }\end{array}$ \\
\hline 50 & $\begin{array}{l}\text { 3- micróbios/verme, pulga, cachorro } \\
\text { 9- micróbios/germes }{ }^{1} / \text { seres unicelulares }\end{array}$ & $\begin{array}{l}\text { - verme, formiga, } \\
\text { micróbios são muito } \\
\text { pequenos e, os vermes } \\
\text { causam doenças. }\end{array}$ \\
\hline
\end{tabular}

QUADRO 2- Fonte: COOPEC, Central-BA, 2009. Reconhecendo os microorganismos - (Os alunos (as) com respostas Insuficientes/Ausentes (I/A) não foram referenciados nesta descrição na questão

03- Existem seres vivos tão pequenos que não podemos ver? Quais? Fale um pouco deles.)

Os estudantes do 20 ano tendem a relacionar os seres pequenos com alguma função, mesmo sem a noção de dimensão física dos mesmos. Tal relação não aparece 3ํ, 4으 e 5으 ano, quando eles atestam a dificuldade de reconhecer a diferença de tamanho entre seres microscópico-macroscópicos, colocando em igualdade micróbio/verme, mosquito e pulga, conforme os exemplos (erros conceituais): pulga é um animal bem pequeno e vive em um cachorro... mosquito, eu não encontro porque ele é muito pequeno... verme, formiga, micróbios são muito pequenos e, os vermes causam doenças. Neste último exemplo (5ano), há um erro conceitual que envolve funcionalidade quando afirmam ser o verme um microorganismo causador de doenças (Castro, 2010).

${ }^{1}$ Germes- (Do lat. Gérmen, 'broto'). (Biol. Ger.) - Expressão clássica para designar qualquer organismo de natureza microscópica ou unicelular, principalmente os microorganismos patogênicos (Soares, 1993, p 192).

Todo germe é um micróbio ou microorganismo, mas nem todo microorganismo ou micróbio é um germe (grifos nossos). 
O número de acertos do 2으 ano em relação à identificação dos micróbios como microorganismos (09 alunos), sendo que 05 destes ainda reconhecem a funcionalidade destes seres, está atrelada a forma com que o conhecimento escolar é mediado com estes estudantes. Freitas (1989) argumenta que, nesta série, os conteúdos escolares são desenvolvidos em sala de aula sem considerar um grande número de critérios. Por isso, de uma maneira geral, as crianças tendem a assimilar os conceitos básicos de seres vivos (classificação e função). Este tipo de aprendizagem caracteriza uma situação formal-simbólica/zero-espontânea, pois existe pouco conhecimento espontâneo para interagir com o conhecimento formal apresentado na escola (PINES; WEST, 1984). Isto indica que os conceitos adquiridos na escola não estão propiciando o desenvolvimento de conceitos espontâneos e/ou explicação de questões do cotidiano pelos alunos.

Segundo Driver (1989) e Byrne e Sharp (2006) , as crianças maiores conhecem os aspectos de organização celular (uni e pluricelular), mas não avançam descrição e funcionalidade de microorganismos. Com base nestes autores, podemos afirmar que os estudantes do 5o ano da COOPEC distinguem, na sua maioria, os seres microscópicos dos macroscópicos, possivelmente pelo contato com os conteúdos escolares de Ciências nas séries anteriores associado a um melhor desenvolvimento na cognição, conforme mostra o Quadro 2 (ver p. 16/17).

Com base em Vygotsky (1991; 2000; 2010), a criança nessa idade escolar inicia a formação de conceitos, pois o pensamento por complexo ou de conceito potencial, característico das séries anteriores (2으, 3 e 4 으 ano) começam a dar lugar ao pensamento abstrato. Este processo deve ser auxiliado pelo professor e pela interação dos colegas no desenvolvimento das atividades realizadas em sala de aula pelas professoras e pesquisador. Com isto, notamos uma possibilidade de aumento da consciência e generalização dos estudantes a partir de seus saberes prévios evidenciados neste trabalho.

Por outro lado, os estudantes do 5 o ano ainda não dominam as diferenças entre organismos microscópicos e macroscópicos pequenos (Castro, 2010, p. 90): "eles acreditam que todos os seres pequenos são formados por uma única célula (unicelulares), ou seja, eles têm dificuldade em identificar organismos unicelulares e pluricelulares a partir do número de células".

Estes dados sugerem a necessidade de um trabalho em sala de aula sobre a caracterização/importância ou identificação/tamanho/função dos organismos pequenos. Acreditamos que o uso de microscópio e de figuras acerca destes conteúdos poderá contribuir sobremaneira para explorar estes conceitos com os meninos (as) da COOPEC, no sentido de facilitar a diferenciação entre os seres vivos que podem ser vistos ou não ao "olho nu", como ponto de partida para tal estudo (Castro, 2010).

Percebemos a necessidade da realização de trabalhos práticos referentes ao ciclo de vida (questão 04) e/ou (re) significação das aulas práticas já desenvolvidas em relação a tal conteúdo, 
principalmente no quarto ano, como por exemplo, metamorfose de insetos e girinos; germinação de sementes e desenvolvimento de plantas locais, de ciclo de vida curto (feijão). Parte desta última prática (germinação) é comumente realizada na escola todo ano, no curso primário como atestam os alunos nos depoimentos prestados. Além disto, é comum no ambiente escolar, próximo à sala de aula, larvas de insetos que tecem seus casulos na horta da escola e na lagoa da cidade, os girinos que se transformam anfíbios adultos, no início das chuvas de verão (Castro, 2010).

Destacamos alguns questionamentos apresentados pelos estudantes da COOPEC, como decorrentes dessas vivências práticas, mas que não foram respondidos pelas professoras: existem vermes microscópicos?; porque os animais não crescem como as plantas?; Como a horta pode ajudar a outros animais? Por que uns seres vivos vivem pouco, enquanto outros vivem muito etc.? Estas proposições nos auxiliaram na formulação de novas questões, bem como no planejamento de atividades/experimentos para fins de continuidade da nossa pesquisa interventiva na COOPEC, em 2010.

Castro (2010) e Castro e Bejarano (2012) informam que os alunos, em geral, usam caracteres externos (folhas, pernas) e/ou internas (pulmão, sangue, seiva) para diferenciar um animal de uma planta (questão 5). em relação a este item, os alunos do 20 e o 50 ano apresentaram indícios de uma diferenciação entre animais e plantas, a partir das funções anatômico/funcionais (analogias), como ilustram o exemplo a seguir (Castro, 2010, p.90; Castro e Bejarano, 2012, p.270): “a planta não tem olho e boca e o animal, tem... a planta tem folha e raízes e o cachorro tem pernas... o animal é carnívoro e a planta, não... os animais têm carnes no corpo e as plantas, folhas e galhos... (alunos das Séries Iniciais da COOPEC)".

Com base em Cunha e Justi (2008), percebemos que os estudantes usam, em geral, analogias anatômico-funcionais na sua diferenciação entre os seres vivos e não vivos. Isto ocorre, segundo Vygotsky (1991; 2000; 2010), porque predominam as relações direto figuradas que denotam o conhecimento espontâneo adquiridos por eles nessa etapa da vida. Entretanto, na explicação de questões funcionais específicas acerca de fotossíntese, respiração, nutrição e crescimento, eles só conseguem avançar em tal distinção a partir do conhecimento escolar (o animal respira oxigênio e a planta gás carbônico).

A maioria dos estudantes demonstra conhecer sobre o hábito alimentar dos seres vivos (questão 06), incluindo eles mesmos, entretanto não conseguem relacionar a alimentação com crescimento de animais e plantas. Eles emitem uma resposta só (tautológica) para este fenômeno sem evidenciar qualquer processo que implica na relação dos alimentos para o crescimento dos organismos vivos (Castro, 2010). De acordo com Vygotsky (1991; 2000; 2010), essas respostas dos estudantes ocorrem por conta da falta do conhecimento escolar (consciência) correspondente aos conteúdos mencionados no excerto anterior. 
Para alunos (as) do 20 ano, obtivemos como respostas mais comum: as plantas se alimentam de água, os animais se alimentam de comida, e o ser humano (ele) se alimenta de água e comida; no 5ㅇ ano, apareceram descrições em que as plantas se alimentam de água, luz e sais minerais; os animais (incluindo ele) se alimentam de fontes alimentares variadas, incluindo os termos carnívoros, herbívoros e onívoros (Castro, 2010).

As crianças, em geral, usaram os conhecimentos imediatos para diferenciar as plantas dos animais. Esse mecanismo ocorre porque, segundo Vygotsky (1991; 2000; 2012), a criança percebe primeiramente as diferenças entre os objetos e /ou fenômenos para depois perceber as semelhanças (Lei das diferenças e semelhanças). No 5o ano, já se evidencia o uso de percepção das semelhanças pelos alunos ao trazerem conceitos novos (em nível escolar) para as perguntas, em relação às séries anteriores. Para o uso dos termos herbívoros, carnívoros e onívoros é requisitado conhecimento de características similares (estrutura do corpo e tipo de alimento) para as espécies de seres vivos assim classificados (grifos nossos).

Por isso, as primeiras impressões sobre os objetos no dia-a-dia são sobremaneira importantes para a formação dos conhecimentos espontâneos a ser disponibilizados na sala de aula. Para ensinar o conceito científico, além de considerar tal "bagagem" e fazer um elo com a mesma, é necessário apresentar os conteúdos científicos na sua forma geral porque assim poderá ser possível manter um dialogo entre os saberes científicos básicos e as formas de pensamento das crianças. Os conteúdos científicos específicos serão apresentados à medida que eles forem se tornando capaz de compreender as explicações científicas para os conteúdos desenvolvidos em sala de aulas e para suas curiosidades levantadas, assimilando ou aceitando-as como mais uma forma de explicação para essas referidas questões (Castro, 2010).

Neste sentido, os dados obtidos acerca dos conhecimentos prévios dos alunos permitiram-nos enunciar algumas questões básicas que poderão ser utilizadas pelas professoras na sala de aula: Quais realmente os seres vivos que não podemos ver? Para que eles servem, ou em que nos trazem prejuízos? Como se explica a diferença de um ser pequeno que não se pode observar ao "olho nu", de um que se pode tocar pegar etc.? Como os alimentos conseguem fazer os vegetais e animais crescer (incluindo o homem)? Para onde vão os alimentos no corpo destes organismos, e o que fazem lá aonde chegam? Como respiram as plantas (Castro, 2010)?

Por fim, numa educação em que se valorizam os fins e não os meios que levam à construção do conhecimento, uma análise nesta dimensão poderá ser referencial para os professores passarem a ver o seu trabalho como uma experiência profissional de valor e interrelacionada com a vida cotidiana de seus discentes. A partir desta concepção, com o trabalho de pesquisa desenvolvido na COOPEC, os estudantes poderão ampliar seus processos de aprendizagem conceitual à medida que seus conhecimentos prévios sobre seres vivos forem (re) significados nas aulas de ciências através de atividades e experiências que atendam a zona de 
desenvolvimento proximal dos alunos. Para este fim, foram planejadas e desenvolvidas aulas práticas na COOPEC desde 2009 (Castro, 2010).

\section{Considerações finais}

A extensão e variedade de conhecimentos dos estudantes da COOPEC discutida neste texto, com base ideário de Vygotsky $(1991 ; 2000 ; 2010)$ no que tange aos conhecimentos espontâneos e científicos e de conceitos biológicos apresentados acerca de seres vivos (Lawson, 1988; Freitas, 1989; Byrne e Sharp, 2006; Sforni; Galuch, 2006; Cunha e Justi, 2008; Popov, 2008; Castro, 2010; Castro e Bejarano, 2012; Castro e Bejarano, 2013) sugeriram as recomendações para o ensino na referida escola em 02 níveis: uso dos saberes das crianças como suporte para o planejamento de aulas teóricas e práticas de ensino; uma possibilidade de ampliação desses conhecimentos na perspectiva de permitir avanços conceituais com respeito ao tamanho e à interação funcional entre os sistemas orgânicos e/ou processos envolvidos.

Os dados diretamente evidenciados na percepção externa dos estudantes poderão ser meios potenciais para o desenvolvimento da compreensão de situações de aprendizagem que implicam na caracterização de assuntos que requisitam abstração, generalização e domínio deliberado de conhecimento. Estes, por sua vez, poderão oferecer uma possibilidade para ampliar os conhecimentos espontâneos dos alunos. O tamanho e funcionalidade de seres vivos foi um aspecto sinalizado por esse trabalho para o qual as crianças demonstraram necessidade de um planejamento de ensino para suprir suas dificuldades de conhecimento concreto para os mesmos (Castro, 2010).

Vemos com isto, uma possibilidade de complementação entre os conhecimentos cotidianos e escolares em seu desenvolvimento como informou-nos Gasparin (2009). Esse papel cabe a escola o dever de realizar essa tarefa de mediação para fins de permitir avanço do conhecimento conceitual dos alunos (Castro, 2010).

Pelo exposto, notamos então, o quão é importante, para escola, conhecer o que as crianças sabem sobre os conceitos gerais de seres vivos e a implicação que estes apresentam para que conteúdos mais específicos como os de tamanho e funções vitais de seres vivos também possam ser aprendidos pelos alunos. Por isso, entendemos a necessidade de incluir, no planejamento escolar (exercício-2010/2011), os conhecimentos espontâneos dos estudantes da COOPEC, como parte dos experimentos e/ou atividades de ensino capazes de aprimorá-los e contribuir para o desenvolvimento conceitual da criança, numa relação mútua entre as influências dos saberes cotidianos e escolares para tal desenvolvimento. Assim, estaremos buscando uma forma de conduzir o ensino para uma compreensão conceitual, ao invés de apenas mobilizá-lo com vistas à memorização ou conhecimento de conceitos que não contribuem para a evolução do saber científico e funcional da criança (Castro, 2010). 


\section{Referências}

BYRNE, J.; SHARP, J. Children's ideas about micro-organisms. School Science Review, v. 88, n. 322, september 2006.

BOGDAN, R.C.; BIKLEN, S. K. A investigação qualitativa em educação: uma introdução à teoria e aos métodos. Portugal: Porto EditoTRra, 1994.

CASTRO, D.R. Estudo de Conceitos de Seres Vivos nas Séries Iniciais. 2010. Dissertação (mestrado)- Universidade Federal da Bahia. Salvador, 2010.

CASTRO, D. R.; BEJARANO, N. R. R. Questionamentos dos estudantes do Ensino Fundamental I sobre funções vitais de animais. EccoS, São Paulo, n. 27, p. 163-173. jan./abr. 2012.

Os conhecimentos alternativos e científicos na área de ciências naturais: uma revisão a partir da literatura internacional. Ciência \& Educação, v. 19, n. 1, p.1015-1028, 2013 (prelo).

CHILDREN'S ideas about living things. [S.I.]: Leads National Curriculum Science Support Project, 1992. Disponível em: <www.learner.org/courses/essential/life/support/

1_Livingthings.pdf >. Acesso em: 20 jan. 2010.

CUNHA, M. de C. C.; JUSTI, R. da S. Analogias sobre nutrição e digestão elaboradas por crianças do ensino fundamental. 2008. Disponível em: <www.fae.ufmg.br/abrapec/viempec/CR2/p8.pdf $>$. Acesso em: 23 mar. 2010.

DRIVER, R. Students' conceptions and the learning of science. International Journal of Science Education, London, v. 11, n. 5, p. 481-490, 1989

DUARTE, N. Conhecimento tácito e conhecimento escolar na formação do professor por que Donald Shon Não compreendeu Lúria. Educação e sociedade, v. 24, n. 83, ago. 2003.

FREITAS, M. A distinção entre ser vivo e ser inanimado: uma evolução por estádios ou um problema de concepções alternativas? Revista Portuguesa de Educação, C.E.E.D. C, Universidade do Minho, v. 2, n. 1, p.33-51, 1989.

GASPARIN, J. L. A construção dos conceitos científicos em sala de aula. Disponível em:< http://www.pesquisa.uncnet.br/pdf/palestraConferencistas/A_CONSTRUCAO_DOS_CONCEITOS_ CIENTIFCOS_EM_SALA_DE_AULA.pdf >. Acesso em: 21 mar. 2009.

LAWSON, A.E. The acquisition of biological knowledge during childhood: cognitive conflict or Tabula rasa? Journal of research in science teaching, v. 25, n. 3, p. 185-199, 1988 
PINES, L., West, L. Compreensão conceitual e aprendizado da ciência: uma interpretação da pesquisa dentro de um arcabouço teórico de fontes do conhecimento, 1984. Mimeografado.

POPOV, O. Estudo dos conceitos e métodos científicos na escola primária. 2008. Disponível em: www.educ.umu.se/ popov/international/TEXTO3.pdf. [consulta, junho, 2010].

SFORNI, M. S. F.; GALUCH, M. T. B. Aprendizagem Conceitual nas Séries Iniciais do Ensino Fundamental. Educar em revista. Curitiba, n. 28, jul-dez, 2006.

SOARES, J. L. Dicionário etimológico e circunstanciado de biologia. São Paulo: Scipione, 1993.

TANNER, K.; ALLEN, D. Approaches to biology teaching and learning: understanding the wrong answers - teaching toward conceptual change. Cell Biology Education, Bethesda, v.

4, n. 2, p.112-117, 2005.

TEIXEIRA, P. M. M. Pesquisas em ensino de biologia no Brasil: um panorama baseado na análise de dissertações e teses (1972- 2004). Programa de Pós-Graduação em Educação, UNICAMP, 2007. Disponível em: http://libdigi.unicamp.br/document/?code=000449571>. Acesso em: 15 abr. 2010. VYGOTSKY, L. S. Pensamento e linguagem. 3. ed. São Paulo: Martins Fontes, 1991.

. A Construção do Pensamento e da Linguagem. São Paulo: Martins Fontes, 2000. . A Construção do Pensamento e da Linguagem. 2. ed. São Paulo: Martins Fontes, 2010.

Darcy Ribeiro de Castro (Professor da Universidade do Estado da Bahia - UNEB/ Campus XXIV- Doutorando em Ensino, Filosofia e Historia das Ciências- Universidade Federal da BahiaUFBA e Universidade Estadual de Feira de Santana-UEFS, dcastro@uneb.br)

Nelson Rui Ribas Bejarano (Professor do Instituto de Química da UFBA e do Programa de Pós-Graduação em Ensino, Filosofia e História das Ciências da UFBA/UEFS- Doutor em educação pela Universidade de São Paulo- USP, bejarano@ufba.br) 